\title{
Correction to: latrogenic atrial septal defect: reassurance or inquisitiveness
}

\author{
Niyada Naksuk $^{1}$ - Samuel J. Asirvatham ${ }^{1,2}$
}

Published online: 5 September 2018

(C) Springer Science+Business Media, LLC, part of Springer Nature 2018

\section{Correction to: Journal of Interventional Cardiac Electrophysiology (2018) 52(2):137-140 https://doi.org/10.1007/s10840-018-0369-4}

The original version of this article unfortunately contained a mistake. The presentation of reference 1 was incorrect. The correct information is given below.

1. Linhart M, Werner J, Stöckigt F, Kohlmann AT, Lodde PC, Linneborn LPT, Beiert T, Hammerstingl C, Borràs R, Nickenig G, Andrié RP, Schrickel JW. High rate of persistent iatrogenic atrial septal defect after single transseptal puncture for cryoballoon pulmonary vein isolation. J Interv Card Electrophysiol. 2018.

The online version of the original article can be found at https://oi.org/ 10.1007/s10840-018-0369-4

Samuel J. Asirvatham

asirvatham.samuel@mayo.edu

1 Division of Cardiovascular Diseases, Department of Medicine, Mayo Clinic, Rochester, MN, USA

2 Department of Pediatrics and Adolescent Medicine, Mayo Clinic, 200 First Street SW, Rochester, MN 55905, USA 